\title{
Ensino de Leitura de Orações por meio de Discriminações Condicionais ${ }^{1}$
}

\author{
Giselda Zanco ${ }^{2}$ \\ Melania Moroz \\ Pontifícia Universidade Católica de São Paulo
}

\begin{abstract}
RESUMO - Teve-se por objetivo ensinar o repertório de leitura, por meio de discriminações condicionais. A proposta, baseada no modelo de equivalência de estímulos e aplicada com software, teve orações como unidade de ensino. Participaram quatro alunos do Ensino Médio (EM). Foram utilizadas orações ditadas (A), imagens (B) e orações escritas (C); também foram utilizadas letras (E) para a construção das palavras componentes das orações. Avaliou-se o repertório antes e após o ensino; testou-se a generalização de leitura para palavras, orações e textos. Comparando-se o desempenho antes e após o ensino, verificou-se que ocorreu leitura generalizada de novas palavras e orações, além de leitura generalizada de textos.Concluiu-se que o procedimento foi efetivo para instalar repertório de leitura em nível mais complexo.
\end{abstract}

Palavras-chave: leitura, discriminações condicionais, equivalência de estímulos, software educativo, ensino médio

\section{Teaching to Read Sentences Using Conditional Discrimination}

\begin{abstract}
The purpose of this study was to teach the reading of sentences by means of conditional discrimination. The method was based on the model of stimulus equivalence and applied with software program, and had sentences as teaching unit. Four high school students were submitted to the following experimental conditions: (A) auditory sentences, (B) images, (C) printed sentences, and (D) letters. The repertoire was evaluated before and after teaching. The results suggested that the students learned reading new words, sentences and texts and that the procedure was effective to install repertoires of reading at higher levels.
\end{abstract}

Keywords: reading, conditional discrimination, stimulus equivalence, educational software, high school

Na educação básica, avaliações sistemáticas (e.g., SAEB, SARESP, PISA) mostram baixo desempenho dos alunos em leitura e escrita, assim como nas habilidades matemáticas. São dados preocupantes, pois vivemos em uma sociedade que exclui quem não domina o código escrito, já que a inserção no mercado de trabalho, a continuidade dos estudos, enfim, o exercício da cidadania demanda a competência do indivíduo no que se refere a esses repertórios.

A Análise do Comportamento tem contribuições a oferecer, a partir dos estudos sobre relações de equivalência. Conforme destacado por Barros (1996), desde o estudo realizado por Sidman, em 1971, outros estão sendo desenvolvidos para buscar não apenas a melhor compreensão da equivalência de estímulos, como também a aplicação desse conhecimento.

Sidman (1971) publicou os resultados de um estudo no qual, por meio de um procedimento de pareamento de acordo com o modelo, ensinou um adolescente de 17 anos com comprometimento intelectual severo a ler palavras. Já fazia parte do repertório prévio do adolescente a relação entre palavra ditada e figura (relação $\mathrm{AB}$ ) e a nomeação das figuras (relação $\mathrm{BD}$ ). Ele, porém, não nomeava as palavras impressas correspondentes (relação CD). Ao

1 Trabalho baseado na dissertação de mestrado da primeira autora, bolsista $\mathrm{CNPq}$

2 Rua José Benjamim de Castro, 75, Apto 21 bloco C, Jd. Vitória, Embu das Artes, SP, Brasil. CEP. 06.826-105.E-mail: giseldazanco@yahoo. com.br adolescente, então, ensinou-se a escolher a palavra escrita correspondente à palavra ditada (relação $\mathrm{AC}$ ). Do ensino dessa única relação, surgiram outros repertórios, como escolher a figura correspondente à palavra escrita (CB), escolher a palavra escrita correspondente à figura $(\mathrm{BC}) \mathrm{e}$ nomear a palavra escrita (CD), ou seja, o adolescente leu palavras com compreensão. Nesse estudo, o sujeito exibiu não apenas o comportamento ensinado (relação $\mathrm{AC}$ ), mas também comportamentos novos (relações $\mathrm{CB}, \mathrm{BC}$ e CD), que não foram alvo do ensino. As relações novas exibidas demonstraram que os estímulos se tornaram equivalentes.

Demonstra-se que há relações de equivalência (Sidman \& Tailby, 1982) quando são evidenciadas as propriedades da reflexividade (A se relaciona a A), da simetria (se A se relaciona a $\mathrm{B}$, então $\mathrm{B}$ se relaciona a $\mathrm{A}$, ou seja, emerge a reversão da relação), da transitividade (se $\mathrm{AB}$ e $\mathrm{BC}$, então $\mathrm{AC}$, ou seja, emerge a relação entre dois estímulos a partir de duas outras relações com um elemento em comum) e da simetria da transitividade.

Conforme salientado por Barros (1996), o estudo da equivalência de estímulos representa a possibilidade de a indução lógica, a criatividade, o significado e a linguagem começarem a ser submetidos a estudos empíricos, antes nunca realizados. Nas palavras de De Rose e Bortoli (2007, p.83), "A especificação operacional oferecida pelo modelo de equivalência de estímulos permitiu que comportamentos simbólicos fossem simulados em laboratório." 
Estudos com relações de equivalência de estímulos, muitos dos quais com uso de computadores e softwares, tem sido realizados para o ensino de diferentes repertórios ampliando-se cada vez mais sua aplicabilidade, conforme se pode acompanhar nas revisões feitas por Domeniconi, Zaine, Aggio e Benitez (2010), Paula e Haydu (2010) e Queiroz, Martins e Gioia (2011). Como já afirmavam Sigurdardottir, Green e Saunders (1990), há mais de duas décadas:

Desde a demonstração inicial de Sidman (1971) numerosas replicações envolvendo ampla variedade de sujeitos, procedimentos e estímulos, foram publicadas. Em geral, esses estudos mostraram que após relações condicionais específicas entre vários estímulos dissimilares terem sido demonstradas, outras propriedades relacionais emergem sem treino direto [...] (p. 47)

Dentre os repertórios estudados, podem ser citados, entre outros, o ensino de frações (Lynch \& Cuvo, 1995; Tulon, 2008); concordância verbal (Cézar, 2010; Iman \& Chase, 1988); leitura de imagens (Garcia \& Aguayo, 2005; Silva, 2010); química orgânica (Cesar, 2014); ensino de $2^{\text {a }}$ língua (Llausas, 2014).

Focalizando os estudos direcionados especificamente ao ensino do repertório de leitura em língua portuguesa (e.g., César, 2009; Fernandes \& Moroz, 2011; Leite \& Hübner, 2009; Llausas, 2008; Medeiros \& Silva, 2002; Peres \& Carrara, 2004; Souza \& De Rose, 2006), verifica-se que a maioria teve como unidade de ensino a palavra, conforme evidenciado em estudo de Pereira (2009), e avaliaram a leitura generalizada com novas palavras, a partir da recombinação de sílabas e/ou letras das palavras ensinadas. Parte deles (e.g., César, 2009; Fernandes \& Moroz, 2011; Llausas, 2008), apesar de proporem o ensino a partir de palavras, utilizaram orações para avaliar a generalização de leitura.

Nesse contexto, o estudo de Ponciano (2006) diferenciase por ter utilizado a oração ${ }^{1}$ como unidade de ensino. Além disso, diferencia-se de outros estudos realizados por analistas do comportamento (e.g., Assis, Baptista, \& Nunes, 2009; Sampaio, Assis, \& Baptista, 2010) sobre o ensino de orações, porém a partir de relações ordinais, em que há sequência entre palavras.

No estudo realizado por Ponciano (2006), tendo como participantes dois alunos de $5^{\mathrm{a}}$ a $8^{\mathrm{a}}$ série do Ensino Fundamental encaminhados para reforço escolar, foram utilizadas orações que, por limitações do software utilizado, tinham no máximo 22 caracteres. Foi aplicada uma etapa de ensino (das seis etapas programadas), utilizando-se seis conjuntos de orações para o treino das relações AB (oração ditada -cena representativa da oração) e AC (oração ditada - oração impressa) e para os testes de emergência das relações BC (imagem- oração impressa), CB (oração impressa - imagem), BD (oração falada pelo participante a partir da imagem), CD (leitura da oração impressa). Outros seis conjuntos de orações foram utilizados no teste

1 Embora Ponciano (2006) utilize o termo "frase", na presente pesquisa é utilizado o termo "oração". Isso porque, segundo Sacconi (2006) "[...] oração é todo e qualquer enunciado que contém verbo ou expressão verbal.” (p. 241); ou seja, a oração gira em torno do verbo. Assim, para ser uma oração, é preciso haver sujeito, verbo e predicado. Como as unidades de ensino utilizadas por Ponciano (2006) e no presente estudo foram compostas pela estrutura sujeito+verbo+predicado, optou-se pelo termo "oração". de leitura generalizada, que foi avaliada com orações novas tanto formadas por palavras de ensino, quanto por orações contendo palavras compostas por recombinação de sílabas e letras das palavras de ensino ("Beto e Sara estão no sofá" é uma oração com três palavras novas). Após 28 dias do encerramento da avaliação leitura generalizada, realizou-se $\mathrm{o}$ teste de manutenção.

Os resultados de Ponciano (2006) demonstraram a possibilidade de efetivar a aprendizagem de leitura a partir de orações, pois tanto nas relações treinadas quanto nas emergentes, os desempenhos foram os esperados $(100 \%$ de acertos). Nos testes de generalização, dos dois participantes que encerraram a programação, apenas um apresentou desempenho no patamar desejado $(80 \%$ de acertos $)$. O desempenho do outro participante foi satisfatório apenas no primeiro teste ( $100 \%$ de acertos), que exigia a leitura de orações novas compostas pelas mesmas palavras treinadas; nos testes que envolviam palavras novas formadas por sílabas de treino, obteve somente $50 \%$ de acertos. Ponciano destaca que isso pode ter ocorrido porque foi realizada uma única etapa de ensino, das seis programadas, sugerindo que um ensino mais longo poderia promover a generalização de leitura de novas orações. Quanto aos testes de manutenção, verificou-se que os percentuais de acerto se mantiveram no mesmo nível do obtido imediatamente após o ensino.

Os achados de Ponciano (2006) indicam a possibilidade de ensinar leitura utilizando-se unidades de ensino mais complexas, como as orações. No entanto, novos estudos devem ser realizados para verificar se tal indicação se sustenta; ainda, algumas perguntas permanecem sem resposta, tais como: quando o ensino é realizado diretamente com orações, ocorre a generalização de leitura para novas orações formadas por palavras não ensinadas? E a generalização de leitura para textos? Ainda, é possível ensinar também a escrita de orações? No caso da escrita, ocorre generalização para orações novas?

Essas questões direcionaram pesquisa que teve o objetivo de ensinar leitura e escrita de orações. Tal proposta de ensino, aplicada com auxílio de software, foi baseada no modelo de equivalência de estímulos e utilizou orações como unidade de ensino. No presente texto, focaliza-se o repertório de leitura.

\section{Método}

\section{Participantes}

Participaram do estudo, com consentimento livre e esclarecido, quatro alunos do Ensino Médio de uma escola pública do estado de São Paulo, localizada no município de Embu das Artes.

\section{Local e materiais}

Foi utilizada a sala de leitura para a seleção dos participantes e avaliação do repertório prévio, sendo utilizada a sala de informática para a aplicação da programação de ensino e testes finais. 
Foram utilizados dois notebooks, o software JClic e fones de ouvido individuais.

Software JClic. De uso livre, permite a inserção de recursos, como sons, imagens, vídeos. Possibilita elaborar atividades de ensino e de avaliação, com uso dos procedimentos de escolha de acordo com o modelo (MTS) e de escolha de acordo com o modelo com resposta construída (CRMTS), com randomização das escolhas, liberação de consequências diferentes para o erro e o acerto e registro do desempenho do aluno.

Instrumentos de avaliação de leitura. O Instrumento de Avaliação de Leitura - Repertório Intermediário (IAL-In), proposto por Ponciano (2006), avalia a leitura de orações. O Instrumento de Avaliação de Leitura - Repertório Inicial (IAL-I), elaborado por Moroz e Rubano (2005), avalia a leitura de palavras, e contém alguns itens de avaliação de escrita. Ambos os instrumentos permitem avaliar relações condicionais entre estímulos sonoros e visuais.

\section{Estímulos}

Orações de ensino. Foram elaboradas orações de acordo com os seguintes critérios: orações formadas por palavras que continham apenas sílabas simples e orações que apresentavam palavras com algumas das complexidades da Língua Portuguesa, como, por exemplo, dígrafo (lh, nh, ch), encontro consonantal, "s" com som "z" e no final de sílaba, "r" entre sílabas e no final de sílaba, "n" entre sílabas.

Os estímulos foram orações ditadas (A), imagens/cenas representativas das orações (B) e orações impressas (C). As orações ditadas foram gravadas sem pausas longas que evidenciassem o início e o final das palavras. Nas orações impressas utilizou-se letra de imprensa, iniciando-se por letra maiúscula e finalizando-se com ponto final.

Nas orações foram usadas 75 palavras, desconsiderados os artigos e proposições, das quais 22 palavras formadas apenas por sílabas simples (compostas por uma vogal e uma consoante, como as palavras pato, abacate, banana e tapete, por exemplo), sendo 12 dissílabas, oito trissílabas e duas polissílabas; as outras 53 palavras continham sílabas complexas (por exemplo, colhe, velho, dinheiro, laranja.), sendo 25 dissílabas, 26 trissílabas e duas polissílabas.

As orações seguiram o padrão utilizado em Língua Portuguesa, com sujeito + verbo + complemento, contendo ainda artigo (a/o) e preposição (no, na, de). Têm-se como exemplo de oração "O pato come banana", na qual "O pato" é sujeito, "come" é verbo e "banana" é complemento.

As orações de ensino foram elaboradas a partir dos seguintes critérios: - orações compostas apenas por palavras de sílabas simples (Fase 1); - orações contendo palavras com "n" entre sílabas (Fase 2); - orações contendo palavras com " "r" em encontro consonantal, entre sílabas, no final da sílaba (Fase 3); - orações contendo palavras com "nh" e "ch" (Fase $4)$; - orações contendo palavras com "lh" (Fase 5). Embora tivessem sido elaborados cinco grupos de orações, o último não foi utilizado em virtude do término do prazo disponível para a realização da pesquisa e do final do semestre letivo.

Para cada fase de ensino, havia 18 orações, organizadas em conjuntos de três orações. Exemplificando, as orações da
Fase 1 foram: $\mathrm{O}$ pato come a banana; $\mathrm{O}$ pato come na sala; $\mathrm{O}$ pato come de bota (Conjunto1); O pato bica a banana. $\mathrm{O}$ pato bica na sala. O pato bica de bota (Conjunto 2); A vaca pisa no abacaxi; A vaca pisa no mato; A vaca pisa no sapato (Conjunto 3); A vaca pega no abacaxi; A vaca pega no mato; A vaca pega no sapato. (Conjunto 4); O galo pega no abacate; $\mathrm{O}$ galo pega na parede; $\mathrm{O}$ galo pega no tapete. (Conjunto 5); $\mathrm{O}$ galo bica no abacate; $\mathrm{O}$ galo bica na parede; $\mathrm{O}$ galo bica no tapete. (Conjunto 6).

Palavras, orações e textos de generalização. Em cada fase de ensino,seguindo os respectivos critérios, foram elaboradas palavras e orações novas, além de textos.Foram 36 palavras (nove para cada fase de ensino) compostas por sílabas presentes nas orações de ensino e por até três sílabas com suas variações (por exemplo, mapa, avenida, cavalo e violino foram palavras formadas por sílabas simples, correspondentes à Fase 1).

Foram elaboradas, ainda, orações contendo apenas palavras de ensino (A vaca come a banana., correspondente à Fase 1, por exemplo) e orações contendo palavras de ensino e palavras não ensinadas, estas compostas por sílabas ensinadas e por suas variações ( $\mathrm{O}$ gato some como cometa, correspondente à Fase 1). Ao todo foram 76 orações.

Finalmente, foram elaborados quatro textos, um para cada fase de ensino. Os textos foram compostos por orações contendo tanto as sílabas presentes nas orações de ensino quanto até seis sílabas novas, sendo: - usadas palavras com sílabas simples (Texto 1); - acrescidas palavras com complexidade "n" (Texto 2); - acrescidas palavras com complexidade "r" (Texto 3); - acrescidas palavras com complexidades "nh", "ch" e "lh" (Texto 4). Cada texto continha duas questões de compreensão, exigindo informações explícitas (textos 1, 2 e 3) e informações que deveriam ser inferidas a partir das apresentadas (Texto 4). Exemplificando: Anita acorda cedo, toma vitamina de abacate, come bolo de laranja, suco de abacaxi e sai. $\mathrm{Na}$ estrada, encontra o Beto de bandana, a Carla de tamanco e o Felipe de bota. E, todo dia, o grupo de amigos anda até a escola. (Texto 3: O grupo)

\section{Procedimento}

Realizou-se o presente estudo, conforme a seguinte sequência: Seleção dos participantes $\rightarrow$ Avaliação do repertório prévio $\rightarrow$ Fase 1 (Pré-Teste --> Ensino + Teste de relações emergentes --> Pós-Teste) $\rightarrow$ Fase 2 (Pré-Teste --> Ensino + Teste de relações emergentes --> Pós-Teste) $\rightarrow$ Fase 3 (Pré-Teste --> Ensino + Teste de relações emergentes --> Pós-Teste) $\rightarrow$ Fase 4 (Pré-Teste --> Ensino + Teste de relações emergentes --> Pós-Teste) $\rightarrow$ Teste de generalização (textos) $\rightarrow$ Avaliação do repertório final.

Iniciou-se com a seleção dos participantes; os selecionados foram submetidos à avaliação do repertório prévio, antes de se iniciar as diferentes fases do procedimento de ensino. Foram realizadas quatro fases de ensino, cada qual focalizando especificidades das palavras em língua portuguesa, conforme descrito anteriormente. Para cada fase de ensino, houve uma avaliação específica do repertório antes de iniciar o ensino (Pré-Teste) e após finalizá-lo (Pós-Teste), 
utilizando-se palavras e orações não ensinadas (estímulos de generalização). Finalizado ensino, avaliou-se a generalização de leitura para textos, encerrando-se com a avaliação do repertório final (reaplicação do IAL-I).

Durante os diferentes testes do presente estudo, incluindo os de emergência de relações, não houve liberação de consequências para as respostas dos participantes; foram programadas consequências apenas para as tentativas de ensino.

As sessões para a realização das atividades (de ensino e de testes) foram de, no máximo, 40 minutos.

Seleção dos participantes. Foi aplicado, individualmente, o IAL-In a 17 alunos que, segundo seus professores, apresentavam leitura e escrita não condizente com o esperado para o Ensino Médio, com o objetivo de selecionar os alunos que não tinham o repertório de leitura de orações. Cinco deles (P10, P12, P13, P14, P17) foram selecionados para participar do presente estudo.

Avaliação do repertório inicial. Os selecionados, e outros dois indicados posteriormente (P18 e P19), foram submetidos ao IAL-I, individualmente, com o objetivo de avaliar os repertórios de leitura e de escrita de palavras. As atividades eram realizadas no computador. Após a avaliação do repertório inicial, apenas P13, P14, P17 e P18 deram sequência às etapas subsequentes do presente estudo.

Pré-teste. Foi realizado, individualmente, antes de cada fase de ensino. Em cada pré-teste, utilizaram-se as palavras e orações de generalização correspondentes à fase de ensino. O pré-teste constituiu-se de: 1) Leitura e escrita de nove palavras de generalização; 2) Leitura de nove e escrita de três orações de generalização compostas pelas palavras ensinadas; 3) Leitura de 10 e escrita de seis orações de generalização compostas por palavras ensinadas e até cinco palavras não ensinadas. As orações foram apresentadas pelo computador nas formas impressa e ditada; o participante foi orientado a ler em voz alta e a escrever numa folha de papel.

Ensino. A proposta de ensino combinou os procedimentos MTS e CRMTS. Foram relacionadas: (A) orações ditadas; (B) imagem/cena representativa da oração; (C) oração impressa, ou seja, foram treinadas as relações $\mathrm{AB}, \mathrm{BC}, \mathrm{CC}$, AC. Também foram treinadas as relações AE (construção da palavra ditada selecionando letras), CE (reprodução da palavra escrita selecionando letras) e $\mathrm{CE}^{*}$ (reprodução da palavra escrita selecionando-se sílabas). Nas relações AE, $\mathrm{CE}$ e CE*, foram utilizados os substantivos, iniciando-se pela quantidade exata de letras/sílabas da palavra (por exemplo, na palavra "sala", utilizaram-se as quatro letras na relação e duas sílabas) e, a cada dois conjuntos de palavras ensinadas, aumentaram-se duas letras/sílabas até que se chegou a seis letras/sílabas além da quantidade necessária para a escrita do substantivo.

Durante o ensino, as respostas corretas foram consequenciadas com uma mensagem por escrito ("Muito bem!", “Parabéns!", “Muito bom!", “Certinho!”, “É isso mesmo!" ou "É isso aí!"), uma figura com animação (gifs) representando contentamento e um estímulo sonoro (vinheta). Para as respostas incorretas, a consequência foi uma mensagem escrita ("Ah, que peninha!", "Que pena, você errou!", “Que pena!”, “Ah, você errou!”, “Que peninha!” ou "Ah, que pena!”) e uma figura com animação (gifs) representando tristeza.

O critério de desempenho no ensino foi de, no mínimo, $90 \%$ de acertos (nas relações CE, CE* e AE, foi de $87,5 \%$ de acertos, correspondentes a um erro). Se o critério não fosse atingido, o participante realizava a Atividade Complementar, retomando todas as relações. No caso das relações $\mathrm{CE}, \mathrm{CE}^{*}$ e AE, foram utilizados, além dos substantivos presentes da oração, as demais palavras, inclusive artigo, verbo e preposição. A Atividade Complementar era realizada até que o critério fosse atingido.

Teste de relações emergentes. Atingido o critério do ensino, o participante foi submetido, individualmente, ao teste de relações emergentes CB (oração impressa - imagem/ cena representativa), $\mathrm{CD}$ (leitura oral de palavra e de oração impressa) e BE (construção de palavra, a partir da imagem/ cena, selecionando letras), AF (escrita manuscrita de palavra ditada) e BF (escrita manuscrita de oração representada pela figura/cena). Atingido o critério de desempenho de emergência (idêntico ao do ensino), ensinou-se um novo conjunto de orações, testando-se a emergência de novas relações, tal como descrito, até que os seis conjuntos de orações de uma dada fase tivessem sido ensinados. Aplicouse, então, o pós-teste da referida fase.

Pós-teste. Avaliou-se o desempenho do participante na leitura e escrita de palavras e orações de generalização correspondentes à fase. Para tanto, reaplicou-se, individualmente, o pré-teste, conforme descrito anteriormente.

Teste de generalização de leitura e compreensão de textos. Esse teste foi realizado após o término do último pósteste da fase de ensino finalizada pelo participante.Os textos 1 e 2 foram destinados a quem finalizou a participação na Fase 2; os textos 1 e 3, a quem finalizou a Fase 3; por fim, os textos 1, 3 e 4, para quem finalizou a Fase 4. O participante recebeu, em letra de imprensa, os textos e as questões de compreensão, de acordo com a última fase de ensino finalizada, com a orientação de que realizasse a leitura em voz alta e respondesse, oralmente e por escrito, as questões de compreensão. A leitura em voz alta permitiu cronometrar o tempo e registrar as possíveis incorreções.

Avaliação do repertório final. Foi reaplicado o instrumento de avaliação do repertório inicial (IAL-I), a fim de verificar possíveis diferenças antes e depois do procedimento de ensino.

\section{Resultados}

Inicia-se a apresentação dos resultados com os relativos ao repertório prévio, avaliado pelo IAL-I. O desempenho

Tabela 1. Porcentagem de acertos, de cada participante, nas relações de leitura de palavras compostas por silabas simples e complexas do IAL-I

\begin{tabular}{lcccc}
\hline & \multicolumn{4}{c}{ Participantes } \\
\hline Relações & P13 & P14 & P17 & P18 \\
CD simples & 89 & 67 & 100 & 89 \\
CD complexas & 67 & 39 & 50 & 50 \\
\hline
\end{tabular}

Nota. CD - leitura de palavras 
dos participantes na leitura (relação $\mathrm{CD}$ ) de palavras com sílabas simples e complexas está indicado na Tabela 1. No que se refere à leitura de palavras com sílabas simples, três participantes (P13, P17 e P18) apresentaram desempenho entre $89 \%$ e $100 \%$ de acertos, sendo que P14 apresentou $67 \%$ de acertos. Os resultados foram inferiores na leitura de palavras com sílabas complexas, pois apenas P13 teve 67\% de acertos, sendo que os demais participantes (P14, P17 e P18) tiveram entre $39 \%$ e $50 \%$ de acertos.

Em suma, no que se refere à leitura oral, verificou-se que realizavam a leitura de palavras quando essas eram compostas por sílabas simples, porém não a realizavam quando as palavras eram compostas por sílabas complexas. Portanto, ficou evidente o baixo desempenho desses participantes, já que eram alunos matriculados regularmente no Ensino Médio, e o IAL-I avaliou o repertório inicial de leitura, focalizando apenas palavras.

\section{Desempenho dos participantes no procedimento de ensino}

Foram 14 semanas de coleta de dados, entre os meses de abril e julho. Nesse período, uma vez que os participantes apresentaram repertórios prévios em níveis diferentes, o mesmo ocorrendo com os ritmos de aprendizagem, P13 realizou quatro fases de ensino em 33 sessões, totalizando 7 h 37 min; P17 realizou três fases em 30 sessões, totalizando $11 \mathrm{~h}$ e $57 \mathrm{~min}$; P14 realizou duas fases de ensino em 24 sessões, totalizando 7 h 55 min e P18 realizou a primeira fase de ensino em oito sessões, totalizando $1 \mathrm{~h} 59 \mathrm{~min}$ (ele deixou de frequentar a escola).

A Figura 1 apresenta os resultados de $\mathrm{P} 13$ nos pré e póstestes das fases de ensino.

Antes do ensino da Fase 1, P13 já apresentou leitura correta de orações, particularmente as que seriam trabalhadas durante o ensino, que eram formadas tanto por palavra com sílabas simples (Fase 1) quanto com algumas complexidades (fases 2 e 3). No entanto, nas orações formadas pelas palavras não ensinadas, em todas as fases apresentou abaixo de $60 \%$ de acertos. Após o ensino, mostrou domínio pleno de leitura de orações, mesmo quando continham palavras não ensinadas

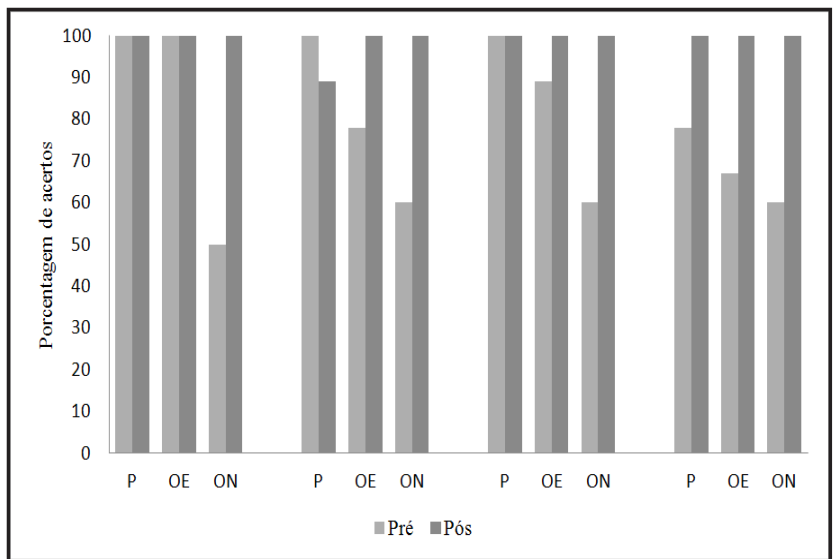

Figura 1. Porcentagem de acertos de P13 na leitura de generalização nos pré e pós-testes nas quatro fases de ensino. $\mathrm{P}$ - palavras; $\mathrm{OE}$ orações com palavras ensinadas; $\mathrm{ON}$ - orações com palavras novas.

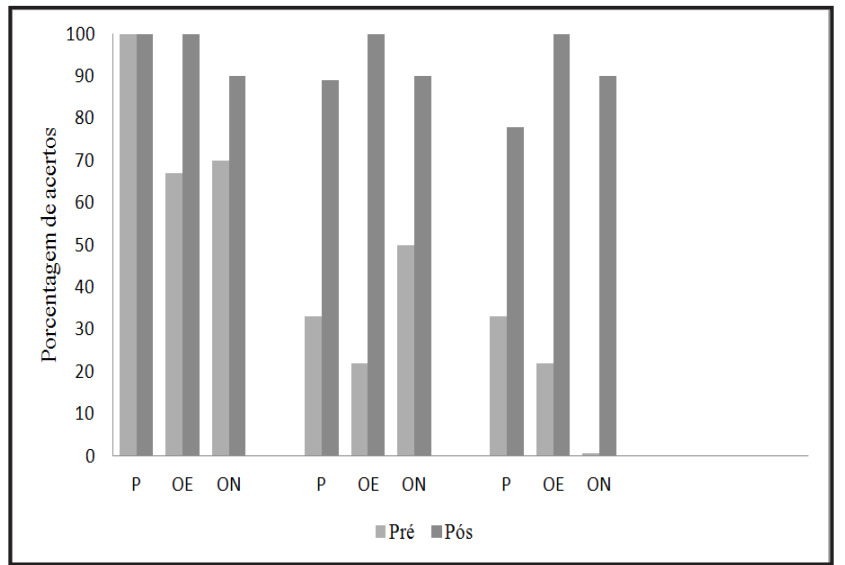

Figura 2. Porcentagem de acertos de P17 na leitura de generalização nos pré e pós-testes nas três fases de ensino. $\mathrm{P}$ - palavras; $\mathrm{OE}$ orações com palavras ensinadas; $\mathrm{ON}$ - orações com palavras novas

formadas por sílabas complexas. Apenas apresentou erro na leitura de generalizaçao de palavras, na Fase 2, pois a palavra"cinco", foi lida como "cinto".

A Figura 2 apresenta os resultados de P17 nos pré e pós-testes das fases de ensino. No caso do P17, verifica-se que seu desempenho melhorou, pois obteve entre $89 \%$ e $100 \%$ de acertos, na quase totalidade das relações avaliadas no pós-teste.O pior resultado foi na leitura de palavras de generalização (da Fase 3, na qual obteve $78 \%$ de acertos, tendo errado a leitura das palavras "prata" e "mar", lidas como "pranta" e "mari". Diferentemente do que havia ocorrido nos pré-testes, nos quais conseguiu ler corretamente orações formadas por palavras com sílabas simples (Fase 1), nos pós-testes leu corretamente praticamente todas as orações, incluindo as formadas por palavras com complexidades da língua portuguesa.

A Figura 3 apresenta os resultados de P14 nos pré e póstestes das fases de ensino.

Quanto a P14, cujo melhor desempenho foi de $67 \%$ de acertos no pré-teste da Fase1, os resultados demonstram que o procedimento de ensino também foi eficiente, pois obteve entre $89 \%$ e $100 \%$ de acertos em todas as relações nos pós-testes. Verifica-se, pois, que o participante apresentou leitura de palavras e orações formadas não apenas por sílabas

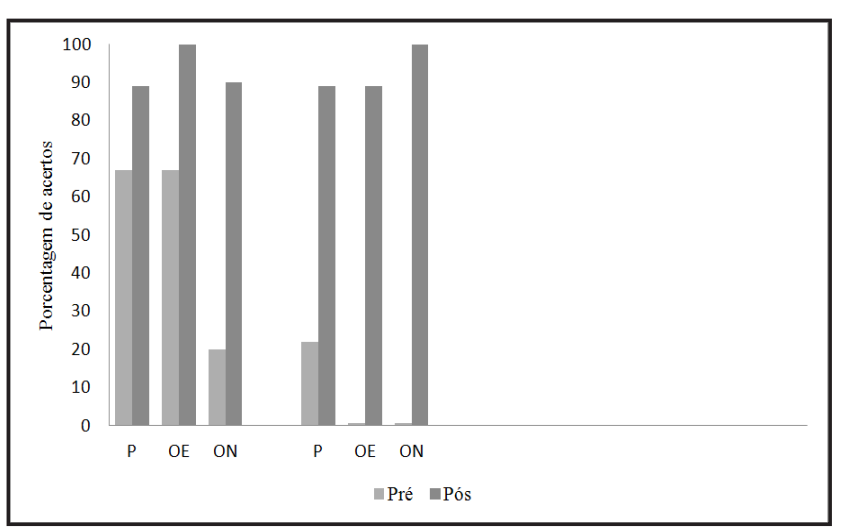

Figura 3. Porcentagem de acertos de P14 na leitura de generalização nos pré e pós-testes nas duas fases de ensino. $\mathrm{P}$ - palavras; $\mathrm{OE}$ orações com palavras ensinadas; $\mathrm{ON}$ - orações com palavras novas 


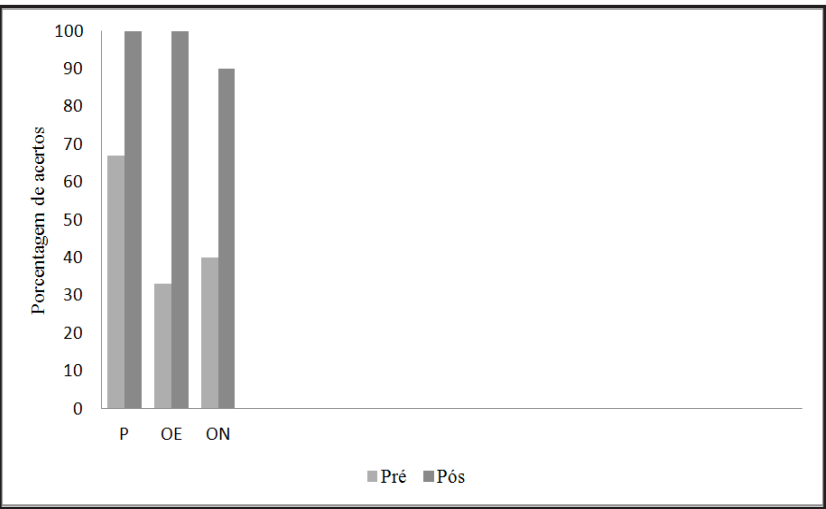

Figura 4. Porcentagem de acertos de P18 na leitura de generalização nos pré e pós-testes na primeira fase de ensino. $\mathrm{P}$ - palavras; $\mathrm{OE}$ orações com palavras ensinadas; $\mathrm{ON}$ - orações com palavras novas simples, mas também contendo a complexidade focada na fase. Porém, esse participante ainda fez leitura silabada, o que indica que não adquiriu fluência. A Figura 4 apresenta os resultados de $\mathrm{P} 18$ nos pré e pós-testes das fases de ensino.

Verifica-se que, mesmo para P18, que realizou uma única fase de ensino, observa-se diferença positiva no desempenho. Isso porque no pré-teste o melhor índice foi de $67 \%$ de acertos, o que ocorreu na leitura de palavras, enquanto que no pós-teste atingiu elevado índice de acertos (entre 90\% e $100 \%$ de acertos) também nas orações, o que indica eficácia do procedimento de ensino também para esse participante.

\section{Desempenho dos participantes no teste de generalização de leitura de textos}

Uma vez que a aplicação respeitou o ritmo de cada participante, os mesmos realizaram a leitura de um texto em comum (Texto 1) e dos textos correspondentes às fases de ensino completadas. Ou seja, P13 fez a leitura dos textos 1,

Tabela 2. Porcentagem de acertos, de cada participante, no teste de generalização de leitura de textos

\begin{tabular}{ccccc}
\hline \multirow{2}{*}{ Participantes } & \multicolumn{4}{c}{ Leitura de textos (\%) } \\
\cline { 2 - 5 } & $\mathrm{T} 1$ & $\mathrm{~T} 2$ & $\mathrm{~T} 3$ & $\mathrm{~T} 4$ \\
\hline P13 & 100 & - & 98 & 100 \\
P17 & 95,5 & - & 98 & - \\
P14 & 89 & 89 & - & - \\
\hline
\end{tabular}

Nota. T - texto

3 e 4; P17 leu os textos 1 e 3; P14 leu os textos 1 e 2; e P18 não realizou esse teste de generalização.

A Tabela 2 ilustra o desempenho dos participantes nos testes de generalização de leitura de textos.

Para realizar a leitura e responder às questões dos três textos, P13 levou 15 minutos. Na leitura dos textos, obteve entre $98 \%$ e $100 \%$ de acertos. Ele cometeu apenas um erro no Texto 3, trocando a palavra "abacaxi” por "abacate". Quanto às respostas dadas às questões de compreensão, o participante acertou ambas as questões dos dois primeiros textos; no Texto 4, as questões foram respondidas incorretamente, as únicas que avaliavam informações que não estavam explícitas no corpo do texto. Pode-se afirmar que demonstrou generalização de leitura e compreensão das informações explícitas no texto.

O participante $\mathrm{P} 17$ levou 10 minutos para fazer a leitura e responder as questões de compreensão. Na leitura do Texto 1 errou duas palavras (obteve $95,5 \%$ de acertos) e na do Texto 3 , errou apenas uma palavra (obteve $98 \%$ de acertos). Os erros de leitura cometidos referem-se à troca da letra "u" por "o", na palavra "tudo", lida como "todo", e à leitura errônea de uma sílaba, nas palavras "esperto" e "estrada", lidas como "espanto" e "escada". Nas perguntas de compreensão dos textos, o participante respondeu todas corretamente. Fica claro que o desempenho de P17 melhorou. Se antes do ensino, na leitura de orações o melhor desempenho havia sido de $70 \%$ de acertos, isso quando elas eram formadas com palavras de sílabas simples, ao final do procedimento apresentou leitura correta e compreensão de textos contendo palavras com complexidades.

O participante P14 levou 20 minutos para fazer a leitura e responder às questões de compreensão. Na leitura dos textos, P14 atingiu $89 \%$ e $98 \%$ de acertos, apesar de a leitura ter sido "silabada". No Texto 1, das 45 palavras, errou cinco, e no Texto 2, das 46 palavras, errou apenas uma. Os erros cometidos por P14, nas palavras que compunham os textos, referem-se à troca ou acréscimo de apenas uma letra. Por exemplo, na palavra "galo", lida como "gato", houve a troca da letra "l" por "t"; outro caso foi na palavra "banco", lida como "branco", onde houve acréscimo da letra " $r$ ". Quanto às respostas para as questões de compreensão dos textos, P14 acertou todas. Assim, para esse participante o procedimento também se mostrou eficaz, uma vez que ao

Tabela 3. Porcentagem de acertos, de cada participante, na leitura de palavras compostas por silabas simples e complexas do IAL-I, antes e depois do procedimento

\begin{tabular}{|c|c|c|c|c|}
\hline \multicolumn{5}{|c|}{ IAL-I } \\
\hline \multirow{3}{*}{ Participantes } & \multicolumn{4}{|c|}{ Leitura de Palavras } \\
\hline & \multicolumn{2}{|c|}{ Simples } & \multicolumn{2}{|c|}{ Complexa } \\
\hline & $\mathbf{A}$ & D & $\mathbf{A}$ & $\mathbf{D}$ \\
\hline P13 & 89 & 100 & 67 & 100 \\
\hline P17 & 100 & 100 & 50 & 94 \\
\hline P14 & 67 & 100 & 39 & 61 \\
\hline
\end{tabular}

Nota. A - antes do procedimento; D - depois do procedimento

final do procedimento demonstrou repertório para leitura e compreensão de textos.

A seguir, apresenta-se o desempenho dos participantes na leitura oral, tanto de palavras com sílabas simples quanto de palavras com sílabas complexas, avaliação feita pelo IAL-I antes e depois do procedimento de ensino.

Na leitura de palavras com sílabas simples, de acordo com a Tabela 3, os três participantes apresentaram desempenho máximo após o ensino; P17 manteve o nível apresentado antes do ensino, sendo que os outros dois melhoraram. Quanto à leitura de palavras com sílabas complexas, P13 e P17 tiveram $100 \%$ e $94 \%$ de acertos, respectivamente; embora P14 tenha apresentado $61 \%$ de acertos, também houve melhora de seu repertório. 


\section{Discussão}

O presente texto teve como objetivo avaliar a eficácia de uma proposta de ensino do repertório de leitura por meio de discriminações condicionais, tendo a oração como unidade de ensino, para alunos que frequentavam o Ensino Médio (EM). Tal proposta foi aplicada com auxílio de software educativo.

$\mathrm{Na}$ avaliação do repertório inicial (IAL-I), os resultados indicaram que os participantes não conseguiram ler palavras contendo complexidades da língua portuguesa, indicando que parte dos alunos que frequenta a escola pública não apresenta o repertório de leitura esperado para a série cursada, tal como tem sido afirmado de forma recorrente na literatura. Por exemplo, César (2009) e Ponciano (2006) também observaram leitura incipiente em alunos de $5^{\mathrm{a}}$ e $6^{\mathrm{a}}$ séries do Ensino Fundamental, ao avaliarem os repertórios prévios de seus participantes. Embora avaliações sistemáticas realizadas no Brasil (e.g., SAEB e SARESP) apontem defasagem dos repertórios de leitura e de escrita dos alunos da escola pública, não se esperava que os repertórios dos participantes do presente estudo tivessem níveis tão rudimentares quanto os detectados, por se tratarem de alunos do Ensino Médio. Claramente, a escola brasileira não vem cumprindo eficientemente seu papel de desenvolver habilidades que são necessárias à sobrevivência digna de qualquer cidadão.

O participante que apresentou os maiores índices de acertos antes do ensino (P13), mas que apresentava dificuldade particularmente na leitura de palavras e orações contendo sílabas complexas, após o procedimento de ensino passou ao pleno domínio das unidades moleculares que formam as palavras, pois conseguiu realizar não apenas a leitura de orações como também a leitura compreensiva de textos. Os resultados permitem supor que o nível de compreensão atingido ainda foi limitado, pois houve compreensão das informações explícitas do texto, não se atingindo a inferência de informações a partir do explicitamente exposto. Novas pesquisas deveriam ser realizadas focalizando os níveis de compreensão de leitura alcançados pelos procedimentos de ensino.

O participante que antes do ensino apresentou baixo índice de acertos na leitura de palavras formadas com sílabas complexas (P17) também passou ao domínio das unidades mínimas formadoras das palavras, pois realizou a leitura de orações e a leitura compreensiva de textos, dois dos quais contendo palavras com sílabas complexas.

O participante, cujo melhor desempenho antes do ensino era na leitura de palavras formadas por sílabas simples (P14), realizou a leitura de orações e também leitura de textos, mostrando estar em processo de aquisição de tal repertório, embora tenha apresentado leitura com índices menores de acertos. Vale destacar que, para esse participante, o efeito do ensino na avaliação final do IAL-I, na leitura das palavras compostas por sílabas complexas, não foi tão evidente quanto o detectado no teste de generalização. Esse pior desempenho no IAL-I muito provavelmente ocorreu pelo fato de que a maioria das palavras com sílabas complexas avaliadas pelo instrumento continha complexidades que não haviam sido ensinadas (já que ele realizou apenas duas fases de ensino), portanto, não se esperava que tivessem sido aprendidas por ele. Supõe-se que, se P14 tivesse realizado outras fases de ensino, focalizando outras complexidades da língua, teria atingido melhor nível de desempenho no IAL-I após o ensino.

Finalmente, o participante que realizou apenas a primeira fase de ensino (18) também melhorou seu desempenho, pois se no pré-teste da fase não conseguia ler orações, passou a fazê-lo no pós-teste. Em suma, todos os participantes apresentaram evolução positiva na leitura, pois conseguiram ler orações e, com exceção daquele que deixou de frequentar a escola, apresentaram leitura compreensiva de textos formados com palavras de treino e com palavras novas, apresentando leitura com compreensão. Pode-se concluir, pelos resultados apresentados, que o procedimento de ensino mostrou-se eficaz para todos os participantes.

Conforme exposto anteriormente sobre a equivalência de estímulos (Sidman,1971; Sidman\&Tailby, 1982), a partir do ensino de algumas relações condicionais entre estímulos emergem relações não ensinadas. Em relação ao repertório de leitura, tal emergência foi confirmada em outros trabalhos (e.g., Fernandes \&Moroz, 2011; Leite \& Hübner, 2009; Medeiros \& Silva, 2002; Peres \& Carrara, 2004; Souza \& De Rose, 2006). No que ser refere ao repertório de leitura de orações, os resultados do desempenho dos participantes indicaram que também houve emergência de leitura generalizada, não apenas de novas orações, repertório em nível mais complexo do que o habitualmente observado nas pesquisas, mas também de textos.

Embora haja estudos realizados com o objetivo de ensinar orações (e.g., Assis et al., 2009; Sampaio et al., 2010), esses têm as relações ordinais como parâmetro de elaboração do procedimento. Já Ponciano (2006) propôs procedimento de ensino de orações a partir do ensino de discriminações condicionais. O estudo de Ponciano (2006) já trazia resultados positivos de ocorrência de leitura para novas orações formadas com as palavras de ensino, embora com efeitos menos evidentes quando as orações eram compostas por novas palavras. O presente estudo confirmou o indicado por Ponciano (2006), ao mostrar que, de fato, ocorre leitura generalizada para novas orações compostas pela recombinação das palavras, de sílabas e de letras, e ampliou os achados ao mostrar que ocorre leitura generalizada também para textos. Evidenciou-se, pois, que podem ser utilizadas unidades de ensino mais amplas do que palavras, atingindo-se níveis mais complexos de leitura.

No que se refere à generalização da leitura, os estudos de César (2009), Fernandes e Moroz (2011) e Lhausas (2008), podem ser destacados por terem avaliado a leitura generalizada para orações, verificando se tal generalização poderia ocorrer a partir do ensino de palavras. Esses autores mostraram que procedimentos de ensino de palavras, baseados no modelo de equivalência de estímulos, favorecem a leitura generalizada não apenas de palavras, mas também de orações, muito embora o nível de generalização na leitura de orações não tenha atingido, para todos os participantes, o critério de desempenho estabelecido. No caso do presente trabalho, os dados também permitem afirmar que o ensino de unidades menores pode levar à leitura generalizada de unidades maiores uma vez que a unidade de ensino foi a oração, sendo tal repertório ampliado para a leitura e compreensão de textos (unidades maiores). Mais ainda, verificou-se que ocorreu também a leitura de unidades 
menores (palavras). Conforme destacado por De Rose (2005), a habilidade de leitura requer que se responda a unidades moleculares e molares. Não importa se o ensino parte de unidades moleculares ou molares; o importante é que o aprendiz leia segmentos tanto molares como moleculares, o que foi demonstrado no presente trabalho.

Alguns aspectos devem ser considerados, quanto à proposta de ensino. Um deles refere-se ao ensino da relação AB. Apesar de a literatura indicar a não necessidade de ensino da relação AB (palavra falada - imagem/cena), uma vez que já faria parte do repertório do aluno, para o presente estudo a relação AB (oração ditada - imagem/cena) foi de grande importância, pois permitiu aos participantes o reconhecimento das imagens/cenas, o que era fundamental para as relações de treino e teste que continham cenas. Se no caso da palavra, a figura quase não apresenta ambiguidade, no caso da oração, o desempenho do participante pode ficar sob controle de diferentes elementos presentes na cena que a representa; assim, na relação $\mathrm{AB}$, ao ditar a oração possibilita-se que o participante fique sob controle do que a cena representa.

Quanto à sequência de ensino, procurou-se iniciar pelas unidades mais simples e avançar para as mais complexas, conforme proposto por Skinner (1968/1975), ou seja, todos os alunos iniciaram o procedimento de ensino de orações com palavras formadas por sílabas simples. Essa decisão foi tomada a fim de facilitar a aprendizagem de orações com sílabas complexas, introduzidas a cada nova fase de ensino.

Outro aspecto a se destacar é que, devido ao fato de as orações procurarem abranger tanto palavras com sílabas simples como com complexidades da língua, algumas orações não corresponderam à realidade como, por exemplo, a oração "A vaca pega no sapato.". Porém, tal fato não se mostrou, durante o procedimento, como variável que pudesse influenciar negativamente o desempenho dos participantes.

Quanto ao tempo despendido na aplicação do proedimento, verificou-se que o menor tempo foi de $7 \mathrm{~h} 37 \mathrm{~min}$ (para a realização de quatro fases de ensino) e o maior foi de $11 \mathrm{~h}$ 57min (para três fases de ensino), o que corresponderia a poucos dias de aula, uma vez que os alunos do EM noturno têm quatro horas diárias de aula. Mesmo com repertórios muito variados, as mudanças ocorreram em tempo relativamente curto, se esse tempo for comparado ao tempo despendido em sala de aula e ao número de anos de inserção dos alunos no processo educativo. Assim, a economia de tempo é visível.

No caso do software usado, tal como enfatizado por Silva (2010), o JClic mostrou-se um recurso importante, pois permitiu a utilização dos procedimentos MTS e CRMTS no ensino de discriminações condicionais, que são de uso comum nos estudos que tem por parâmetro a área de equivalência de estímulos; além disso, possibilitou o trabalho com orações de diversos tamanhos.

Assim como ocorre com outros recursos, o JClic apresenta vantagens e desvantagens. Entre as vantagens está a possibilidade de inserção de imagens e sons de diferentes formatos e tamanhos, além da possibilidade de se trabalhar com orações e textos, sem a preocupação com a quantidade de caracteres. Quanto às desvantagens, há o fato de se gastar muito tempo na inserção da programação; outra desvantagem diz respeito ao relatório, pois apesar de apresentar as porcentagens de erros e de acertos, não apresenta qual foi a escolha incorreta feita pelo participante. Esse é um aspecto a considerar, caso se queira utilizar tal recurso em futuras pesquisas.

Conforme destacado por Stromer, Mackay e Stoddard (1992), propostas de enisno baseadas na equivalência de estímulos tem grande potencial de aplicabilidade no campo educacional. Diante dos resultados satisfatórios apresentados, pode-se defender que programações aplicadas com o auxílio de recursos multimídias e com unidades de ensino maiores (no caso orações) podem ser de grande valia para professores que procuram formas eficientes de ensinar alunos que, inseridos no processo escolar, não apresentam o repertório de leitura esperado. Além de respeitar o ritmo individual, essas programações mantêm os alunos em constante interação com o que está sendo ensinado e apresenta feedback imediato, condições que, embora necessárias para a ocorrência do aprendizado, dificilmente estão presentes no cotidiano da sala de aula.

Outros estudos, tendo orações como unidades de ensino, devem ser realizados, a fim de verificar se tais resultados são replicados, e de aproximar, cada vez mais, os conhecimentos derivados das pesquisas em Análise do Comportamento às práticas da sala de aula. Assim, será possível oferecer contribuição efetiva a uma educação de qualidade para todos.

\section{Referências}

Assis, G. J. A., Baptista, M. Q. G., \& Nunes, A. L. M. (2009). Formação de sequências: aspectos conceituais e metodológicos. Interação em Psicologia, 13, 215-127.

Barros, R. S. (1996). Análise do comportamento: da contingência de reforço à equivalência de estímulos. Cadernos de Textos de Psicologia, 1, 7-14.

César, M. A. (2009). Ensino de leitura: uma proposta para aperfeiçoar o desempenho de alunos de $5^{a}$ e $6^{a}$ séries do EnsinoFundamental, com uso de software educativo (Unpublished master's thesis). Pontifícia Universidade Católica de São Paulo, São Paulo.

César, M. A. (2014). Química orgânica: proposta de ensino com base no modelo de equivalência de estímulos (Unpublished doctoral dissertation). Pontifícia Universidade Católica de São Paulo, São Paulo.

Cézar, E. H. C. (2010). Concordância verbal: uma proposta de ensino de discriminações condicionais utilizando software educativo (Unpublished master's thesis). Pontifícia Universidade Católica de São Paulo, São Paulo.

De Rose, J. C. (2005). Análise comportamental da aprendizagem de leitura e escrita. Revista Brasileira de Análise do Comportamento, 1, 29-50.

De Rose, J. C. \& Bortoloti, R. (2007). A equivalência de estímulos como modelo do significado. Acta Comportamentalia, 15, 83-102. 
Domeniconi, C., Zaine, I., Aggio, N., \& Benitez, P. (2010). Populações da terceira idade e equivalência de estímulos: uma revisão bibliográfica. In M.M.C.Hübner, M.R.Garcia, P. R. Abreu, E. N. P. de Cillo, \& Faleiros, P.B. (Eds.), Sobre Comportamento e Cognição (pp. 299-308). Santo André - SP: ESETec - Editores Associados.

Fernandes, M. A. P., \& Moroz, M. (2011). Ensino de leitura para alunos do Ensino Fundamental - proposta com base na Análise do Comportamento. Psicologia da Educação, 32, 47-68.

García, R. F.,\& Aguayo, L. V. (2005). Formación de categoríaspictórias a través de relaciones de equivalencia. Psicothema, 17, 83-89.

Iman, A. A., \& Chase, P. N. (1988). A stimulus equivalence model of syntactic clases. Revista Mexicana de Analisis de la Conducta, 14, 11-21.

Leite, M. K. S., \& Hübner, M. M. C. (2009). Aquisição de leitura recombinativa após treinos e testes de discriminações condicionais entre palavras ditadas e impressas. Psicologia: Teoria e Prática, 11, 63-81.

Llausas. R. V. (2008). Avaliação de uma proposta de ensino de leitura e escrita para jovens e adultos utilizando software educativo (Unpublished master's thesis). Pontifícia Universidade Católica de São Paulo, São Paulo.

Llausas. R. V. (2014). Avaliando uma proposta de Espanhol por meio de discriminações condicionais (Unpublished doctoral dissertation). Pontifícia Universidade Católica de São Paulo, São Paulo.

Lynch, D. C. \& Cuvo, A. (1995). Stimulus equivalence instruction of fraction - decimal relations. Applied Behavior Analysis, $28,115-126$

Medeiros, J. G., \& Silva, R. M. F. (2002). Efeitos de testes de leitura sobre a generalização em crianças em processo de alfabetização. Psicologia: Reflexão e Crítica, 15, 587-602.

Moroz, M., \& Rubano, D. R. (2005). Uma proposta de Instrumento de Avaliação de Leitura - Repertório Inicial (IAL-I). In M.Moroz (Ed.), Relatório parcial do projeto de pesquisa Avaliando uma proposta de ensino: a leitura em foco. São Paulo: Programa de Estudos Pós-Graduados em Psicologia da Educação da PUC-SP.

Paula, J. B. C., \& Haydu, V. B. (2010). Revisão bibliográfica de pesquisas brasileiras sobre equivalência de estímulos. Psicologia: Teoria e Pesquisa, 26, 281-294.
Pereira, T. A. G. (2009). Equivalência de estímulos e ensino de leitura: uma análise da produção nacional da Análise do Comportamento publicada de 1989 a 2007 (Unpublished master's thesis). Pontifícia Universidade Católica de São Paulo, São Paulo.

Peres, E. A., \& Carrara, K. (2004). Dificuldades de leitura: aplicação da metodologia de equivalência de estímulos. Psicologia da Educação, 18, 77-94.

Ponciano, V. L. O. (2006). Ensino de leitura com uso de software educativo: novas contribuições (Unpublished doctoral dissertation). Pontifícia Universidade Católica de São Paulo, São Paulo.

Queiroz, A. B. M., Martins, T. C., \& Gioia, P. S. (2011). Teses e dissertações sobre leitura recombinativa disponíveis eletronicamente: algumas características da produção brasileira. Psicologia: Teoria e Prática, 13, 180-193.

Sacconi, L. A. (2006). Nossa gramática contemporânea - Teoria e Prática. São Paulo: Escala Educacional.

Sampaio, M. E. C., Assis, G. J. A., \& Baptista, M. Q. G. (2010). Variáveis de procedimentos de ensino e de testes na construção e leitura de sentenças com compreensão. Psicologia: Teoria e Pesquisa, 26, 145-155.

Sidman, M. (1971). Reading and auditory visual equivalences. Journal of Speech and Hearing Research, 14, 5-13.

Sidman, M., \&Tailby, W. (1982). Conditional discrimination vs. matching to sample: An expansion of the testing paradigm. Journal of the Experimental Analysis of Behavior, 37, 5-22.

Sigurdardottir, Z. G., Green, G., \& Saunders, R. R (1990). Equivalence classes generated by sequence training. Journal of the Experimental Analysis of Behavior, 53, 47-63.

Silva, J. S. F. (2010). A leitura de imagens no ensino de arte com uso de software educativo: formação de categorias pictórias por meio de relações de equivalência (Unpublished master's thesis). Pontifícia Universidade Católica de São Paulo, São Paulo.

Skinner, B. F (1975). Tecnologia do ensino. São Paulo: EPU (Trabalho original publicado em 1968)

Souza, D. G., \& De Rose, J. C. (2006). Desenvolvendo programas individualizados para o ensino de leitura. Acta Comportamentalia, 14, 77-98.

Stromer, R., Mackay, H. A. \& Stoddard, L. T. (1992).Classroom applications of stimulus equivalence technology. Journal of Behavioral Education, 2, 225-256.

Tulon, A. S. (2008). Ensino de frações e equivalência de estímulos: um estudo com uso de software educativo (Unpublished master's thesis). Pontifícia Universidade Católica de São Paulo, São Paulo. 